\title{
Fantasia (1940), Walt Disney e a imprensa no Estado Novo
}

Nayara Régis Franz ${ }^{1}$

\begin{abstract}
RESUMO: O cinema está inserido nas mediações culturais desde as primeiras décadas do século XX e quando analisado na forma de documento histórico, nos auxilia na compreensão de imagens e representações de seu tempo. Durante o final da década de 1930 e início de 1940, a indústria cinematográfica estadunidense estava quase que inteiramente voltada para os esforços da Segunda Guerra Mundial, assim como para a Política de Boa Vizinhança que os Estados Unidos exerciam na América Latina. Hollywood produzia filmes, séries, animações e propagandas para o governo estadunidense divulgar o American Way of Life no continente. Nesse contexto, Walt Disney atuou como um dos principais embaixadores da Política de Boa Vizinhança no Brasil, quando esteve no país em agosto de 1941, patrocinado pelo Office of the Coordinator of Inter-American Affairs, o OCIAA, para promover o lançamento da animação Fantasia (1940) nas capitais do Rio de Janeiro e São Paulo. O nosso principal objetivo neste trabalho é analisar parte do processo de hegemonia estadunidense no Brasil a partir de alguns meios de comunicação e cultura, que preconizavam a democracia mediante um discurso de modernidade e civilização. A partir de alguns periódicos nacionais da época, podemos analisar a recepção da mídia brasileira em relação à Walt Disney e Fantasia que, assim como o cinema, atuaram não apenas como meios, mas também como mediações entre os interesses dos governos estadunidense e brasileiro.
\end{abstract}

Palavras-chave: História do Cinema. Walt Disney. Política de Boa Vizinhança. Estado Novo.

\section{Fantasia (1940), Walt Disney and the press in the Estado Novo}

\begin{abstract}
Cinema has been inserted in cultural mediations since the first decades of the 20th century and when analyzed in the form of a historical document, it assists us in the understanding of images and representations of its time. During the late 1930s and early 1940s the American film industry was almost entirely geared to the efforts of World War II as well as to the Good Neighbor Policy of the United States in Latin America. Hollywood produced films, series, animations and advertisements for the US government to publicize the American Way of Life on the continent. In this context, Walt Disney acted as one of the main ambassadors of the Good Neighbor Policy in Brazil, when he visited the country in august 1941, sponsored by the Office of the Coordinator of Inter-American Affairs, OCIAA, to promote the launch of Fantasy (1940) in the capitals of Rio de Janeiro and São Paulo. Our main objective in this work is to analyze part of the process of American hegemony in Brazil from some media and culture, which advocated democracy through a discourse of modernity and civilization. From some national periodicals of the time, we can analyze the reception of the Brazilian media in relation to Walt Disney and Fantasia which, like cinema, acted not only as means but also as mediations between the interests of the US and Brazilian governments.
\end{abstract}

Keywords: Cinema's history. Walt Disney. Good Neighbor Policy. Estado Novo.

- Enviado em 15/03/2017

- Aprovado em 18/06/2017

\footnotetext{
${ }^{1}$ Bacharela e licenciada em História pela Universidade Federal de Santa Catarina. Atualmente é mestranda no Programa de Pós-Graduação em História Cultural na mesma instituição. O presente trabalho foi realizado com apoio do CNPq, Conselho Nacional de Desenvolvimento Científico e Tecnológico - Brasil. E-mail: nayarafranz@gmail.com
} 


\section{Introdução}

O contexto da nossa pesquisa situa-se entre a Segunda Guerra Mundial e os objetivos da Política de Boa Vizinhança na relação entre Estados Unidos e Brasil. O nosso principal objeto de estudo concentra-se em Fantasia, uma animação musical lançada pelo estúdio Walt Disney Productions em 1940. Pensamos em Walt Disney enquanto um empresário estadunidense que, patrocinado pelo Office, ${ }^{2}$ neste período atuou como embaixador desta política na América Latina. Na primeira de suas viagens ao Brasil, em agosto de 1941, Disney esteve por cerca de três semanas visitando as capitais de Rio de Janeiro e São Paulo, cumprindo os projetos do governo estadunidense e estreando Fantasia.

Internamente, o Brasil vivia o regime do Estado Novo (1937-1945), conduzido pelo presidente Getúlio Vargas. O Estado Novo pode ser considerado um Estado de Exceção, à medida que foi instaurado por um golpe, em 10 de novembro de 1937, e concentrava todos os poderes na figura do presidente da República, sendo, portanto, um regime autoritário. Desde o início do Estado Novo, a imprensa nacional estava sujeita ao regime da censura, controlada pelo DIP, o Departamento de Imprensa e Propaganda. Em uma nota do Jornal do Brasil de seis de novembro de 1937, Vargas publicou a seguinte frase em relação ao que pensava sobre a imprensa: "Sempre considerei a Imprensa como instrumento indispensável à boa administração dos negócios públicos, e tudo tenho feito para prestigiá-la, acatando á crítica jornalística, quando de boa fé e construtiva" ${ }^{3}$. Ou seja, quando as notícias não eram consideradas por Vargas como de "boa fé e construtivas", o jornal ou revista responsável era barrado pela censura estadonovista.

Criado em dezembro de 1939 e extinto em maio de 1945, o DIP foi estrategicamente elaborado para atuar como a capacidade de intervenção do Estado na esfera dos meios de comunicação e da cultura. Esta era uma organização vinculada diretamente à Presidência da

\footnotetext{
${ }^{2}$ O Office of the Coordinator of Inter-American Affairs, o OCIAA, ou o Escritório de Coordenação de Assuntos Interamericanos; era um órgão subordinado ao Conselho de Defesa Nacional dos Estados Unidos, que atuou neste período em nome da Política de Boa Vizinhança. O órgão era coordenado pelo milionário Nelson Rockefeller (19081979), neto do fundador da Standard Oil, empresa petrolífera de grande importância que estava presente em vários países da América Latina.

3 VARGAS, Getúlio. "Como o presidente da República se refere a imprensa". In: Jornal do Brasil. Rio de Janeiro: Fundação Biblioteca Nacional, 6 nov. 1937, p. 11.
} 
República, que transmitia o modelo de centralização do governo com cargos de confiança atribuídos diretamente por Vargas e continha seis divisões: Divulgação; Radiodifusão; Cinema e Teatro; Turismo; Imprensa; e Serviços Auxiliares. No setor da imprensa, segundo a historiadora Maria Helena Capelato, "a partir de 1940, 420 jornais e 346 revistas não conseguiram registro no DIP"4. Todos os veículos de oposição ao regime foram fechados ou sentiram-se obrigados a viver na clandestinidade. O DIP não deveria admitir notícias de oposição política, problemas de origem econômicas do país, divulgação de acidentes, crimes, corrupção; em resumo, tudo o que poderia passar uma imagem negativa do regime ${ }^{5}$.

Podemos afirmar, portanto, que durante o Estado Novo houve uma grande perda de direitos de organização e de expressão do pensamento ${ }^{6}$, no sentido de que foi um momento de interrupção do processo de democratização do Brasil. Ao final do regime, o rigor da censura desagradava à boa parte da imprensa que, em 1945, começou a contribuir para a saída de Vargas, da mesma maneira que anteriormente (1937) havia preparado o terreno para o golpe deste presidente ${ }^{7}$. Mas durante a maior parte do Estado Novo, jornais e revistas, eram obrigados a passar uma boa imagem do governo, apresentando, por exemplo, discursos e fotos do presidente, sempre de maneira positiva. A linguagem da imprensa era construída para enfatizar a popularidade do presidente e exaltar a figura do líder brasileiro em tempos de guerra. Essas afirmações eram diárias, mas para citarmos apenas uma, no primeiro dia do ano de 1939, o jornal Diário Carioca exaltava as qualidades de Vargas em relação ao Exército e a Marinha do Brasil:

O sr. Getúlio Vargas passará, indiscutivelmente, para a história da República, como o renovador da estructura material das forças de terra e mar. [...] E bastou a iniciativa do senhor Getulio Vargas para que surgissem as quilhas velozes que singram os mares desfraldando a nossa bandeira aos ventos de todos os quadrantes. [...] E o sr. Getúlio Vargas estendeu, tambem, a sua acção ao Exercito. Estimulou as industrias bellicas, renovou o material, apoiou a moto-mecanização, elevou as forças aéreas, e determinou a

\footnotetext{
${ }^{4}$ CAPELATO, Maria Helena. Propaganda Política e Controle dos Meios de Comunicação. In: PANDOLFI, Dulce (Org.) Repensando o Estado Novo. Rio de Janeiro: Fundação Getúlio Vargas, 1999, pp. 172-173.

${ }^{5}$ CAPELATO, Maria Helena. Propaganda Política e Controle dos Meios de Comunicação. In: PANDOLFI, Dulce (Org.) Repensando o Estado Novo. Rio de Janeiro: Fundação Getúlio Vargas, 1999, p. 175.

${ }^{6}$ Cf. CHAMBÔ, Pedro Luis. O Estado de Exceção como Regra - um estudo histórico-constitucional do Estado Novo (1937-1945). R. Fac. Dir. Univ. São Paulo, v. 108, pp. 117-128, 2013.

${ }^{7}$ Cf. CAPELATO, Maria Helena. A imprensa na história do Brasil. São Paulo: Contexto/EDUSP, 2 edição: 1994, PP. 49-50.
} 
construç̧ão de quartéis, integrando, assim, o exercito na sua verdadeira finalidade. Em pleno Estado Novo, o Exercito e a Marinha, apoiando como sempre apoiou o governo do sr. Getulio Vargas, trabalharam pela grandeza e pelo progresso da nação [sic $]^{8}$

Segundo Capelato, este tipo de linguagem evitava o surgimento de oposições, porque não admitia contestação, sendo o seu poder muito eficaz ${ }^{9}$. A partir da mídia, o Estado Novo comandado por Vargas procurava passar uma imagem favorável de si mesmo, afirmando que tudo ocorria perfeitamente bem para a população. No entanto, é importante lembrar que este poder de manipulação da imprensa não é recebido por todas as pessoas da mesma maneira. A recepção não é passiva, e sim ativa. Apesar das representações oficiais, os leitores constroem a sua própria interpretação em relação ao que recebem. Ainda assim, é a notória importância da propaganda política nessa época para a sustentação do poder de $\operatorname{Vargas}^{10}$.

Mas a propaganda estadonovista não vivia apenas de jornais e revistas. Rádio e cinema também faziam este papel, provavelmente com mais abrangência, se considerarmos que naquele momento a taxa de analfabetismo entre a população com 15 anos ou mais era de $56 \%{ }^{11}$. Partimos do ponto de vista de que imprensa e cinema (assim como televisão, rádio, etc.) não são apenas meios, mas mediações culturais, pois estão envolvidos na construção e desconstrução da sociedade. A aliança entre Estados Unidos e Brasil ocorreu a partir destas mediações, numa relação de trocas políticas, econômicas e culturais. Em virtude disto, em janeiro de 1941 o DIP proibiu qualquer crítica aos Estados Unidos na imprensa nacional e foi responsável pela maior parte da difusão da propaganda estadunidense no Brasil, obrigando os meios de comunicação, por sua vez, a levarem a informação e a formação da opinião simpática à política dos bons vizinhos. A

\footnotetext{
${ }^{8}$ SUCENA, Heider Villares. "O Brasil, Potencia Militar". In: Diário Carioca. Rio de Janeiro. Fundação Biblioteca Nacional, 01 jan. 1939, p. 14.

${ }^{9}$ Cf. CAPELATO, Maria Helena. Propaganda Política e Controle dos Meios de Comunicação. In: PANDOLFI, Dulce (Org.) Repensando o Estado Novo. Rio de Janeiro: Fundação Getúlio Vargas, 1999, p. 171.

${ }^{10}$ A esse respeito, podemos tomar de exemplo o fato de que ainda hoje a memória de Getúlio Vargas permanece, para muitos brasileiros, de maneira positiva, em virtude dos benefícios que este proporcionou aos trabalhadores, principalmente. Mas a luta destes trabalhadores para alcançar estes direitos e toda a repressão política do Estado Novo são menos lembradas, provavelmente porque foram menos veiculadas.

11 Fonte: IBGE, Censo Demográfico 2010, p. $32 . \quad$ Disponível em: <http://www.ibge.gov.br/home/presidencia/noticias/imprensa/ppts/00000008473104122012315727483985.pdf> Acesso em 10 de outubro de 2016.
} 
ideia era o Brasil passar uma imagem favorável dos Estados Unidos para a sua população e que este país fizesse o mesmo sobre o Brasil a partir das suas mídias, propagandeando, por exemplo, o café brasileiro nos jornais estadunidenses, e repercutindo a música brasileira nos rádios, etc.

Quando consideramos o intercâmbio cultural entre as duas sociedades, porém, houve uma influência praticamente única, de lá para cá, ou como afirma o historiador Gerson Moura: “Em poucas palavras, os brasileiros iam aos Estados Unidos para aprender; os americanos vinham ao Brasil para ensinar"12. A partir de 1941 estiveram no Brasil várias missões dos bons vizinhos, compostas por intelectuais, professores, jornalistas, artistas, militares, empresários, cientistas, etc. Nesse período os brasileiros incluíram no seu cotidiano a coca-cola, os hamburgers, os chiclets, o jeans, e o ok, por exemplo ${ }^{13}$. A nova maneira de ser, sentir, explicar e expressar o mundo era marcada pela influência conhecida como American way of life (estilo de vida americano), pois como afirmam Ariel Dorfman e Armand Mattelart:

Por detrás da Coca-Cola, está toda uma estrutura de aspirações, pautas de comportamento; portanto, de um tipo de sociedade presente e futura, e uma interpretação do pretérito. Ao importar o produto que se concebe, se engarrafa, se etiqueta (e cujos benefícios econômicos retornam ao tio), importa-se também as formas culturais desta sociedade, mas nunca seu conteúdo, ou seja, fatores que permitiram seu crescimento industrial ${ }^{14}$.

A hegemonia estadunidense presente no Brasil, então, está diretamente relacionada com as mediações culturais, afinal, os meios são os principais agentes de interação entre os grupos ${ }^{15}$. Segundo José Martín-Barbero, a cultura:

12 MOURA, Gerson. Tio Sam Chega ao Brasil: A penetração cultural americana. São Paulo: Brasiliense, 2a edição, 1985, p. 24.

13 Ibidem, p. 03.

14 DORFMAN, Ariel; MATTELART, Armand. Para Ler o Pato Donald: Comunicação de massa e colonialismo. Tradução de Álvaro de Moyá. 2a ed. Rio de Janeiro: Paz e Terra, 1980, p. 145.

${ }^{15}$ MARTÍN-BARBERO, Jesús. Dos meios às mediações: comunicação, cultura e hegemonia. Tradução de Ronald Polito e Sérgio Alcides. Rio de Janeiro: Editora UFRJ, 2009, p. 112. 
[...] se converteu em espaço estratégico da hegemonia, passando a mediar, isto é, encobrir as diferenças e reconciliar os gostos. [...] uma mediação que encobre o conflito entre as classes produzindo sua resolução no imaginário, assegurando assim o consentimento ativo dos dominados. [...] integrando ao mercado as novas demandas das $\operatorname{massas}^{16}$.

Cinema, imprensa, rádio e música exerciam as mediações entre os sujeitos envolvidos. Conquistar os brasileiros por meio da cultura era o principal objetivo do governo estadunidense nesta época, pois era a melhor maneira de garantir a hegemonia e ainda manter amizades. A partir das mediações culturais, o Office (e no caso do Brasil o Office em parceria como o DIP) veiculava o American way of life como uma representação de modernidade, civilização e progresso, discursando que à medida que levaria o capitalismo industrial à América Latina, consequentemente faria com que a região abandonasse ou amenizasse a sua posição inferior.

Segundo a historiadora Mary Anne Junqueira, neste período a visão estadunidense do restante da América estava intimamente atrelada ao imaginário local, chamado Wilderness, que significava "deserto, ermo, sertão, solidão, região inculta, imensidão, grande quantidade, multidão, miscelânea"17. O Wilderness era relacionado ao Oeste estadunidense do século XIX que, de acordo com o mito que emergiu deste evento histórico, estava além da fronteira, onde os Pioneiros encontrariam novas terras e oportunidades. O Pioneiro é o sujeito que levaria a civilização até este território ${ }^{18}$. Ao analisar artigos de Seleções ${ }^{19}$, Junqueira constatou que durante a Segunda Guerra Mundial essa visão era adotada pela revista quando se referia à América Latina, considerada

\footnotetext{
${ }^{16}$ Ibidem, p. 175.

17 JUNQUEIRA, Mary Anne. Ao Sul do Rio Grande. Imaginando a América Latina em Seleções: oeste, wilderness e fronteira (1942-1970). Bragança Paulista: EDUSF, 2000, p. 58.

18 Ibidem, p. 68.

${ }^{19}$ Reader's Digest foi uma revista estadunidense de grande circulação na América Latina. No Brasil começou a ser veiculada em 1942, com o título de Seleções.
} 
"pouco civilizada", formada por territórios despovoados - com uma população primitiva, composta basicamente de pobres e mestiços - fez com que a região fosse interpretada como um ambiente propício à penetração do inimigo externo alemão e japonês ${ }^{20}$.

Dessa maneira, o estadunidense era representado como civilizado, superior, moderno; e o latino-americano como incivilizado, inferior, atrasado. Acontece que essa civilização estadunidense "está relacionada ao comércio, à obtenção de lucro de qualquer espécie"21. Nesse momento, Hollywood já era a 14a maior indústria dos Estados Unidos ${ }^{22}$ e o cinema o mais influente dos meios de cultura do país. O governo apostou na capacidade de intervenção ideológica por meio do cinema, quando percebeu que o mundo de sonhos que essa indústria vendia poderia render um lucro muito real para a economia do país, assim como se demonstrou essencial para a expansão da cultura estadunidense pelo mundo. Além do fato de que as portas estavam abertas para Hollywood, uma vez que desde a Primeira Guerra Mundial países como França, Inglaterra e Alemanha interromperam a maior parte da sua produção fílmica em razão do conflito. Hollywood, então, já conseguia dominar 95\% do total de filmes exibidos na América Latina no período 23 .

Dessa maneira, o cinema hollywoodiano já era sinônimo de modernidade e progresso no Brasil desde os anos $1920^{24}$, mas foi no final da década de 1930 e início da década de 1940, em função da Segunda Guerra Mundial e da propaganda estadunidense que chegava ao Brasil, entre outros meios pelo cinema, que este passou a ser percebido também como um instrumento político, inclusive pelo DIP, que começou a exigir que todos os filmes adquirissem um certificado

\footnotetext{
${ }^{20}$ JUNQUEIRA, Mary Anne. Op. cit., p. 146.

21 JUNQUEIRA, Mary Anne. Ao Sul do Rio Grande. Imaginando a América Latina em Seleções: oeste, wilderness e fronteira (1942-1970). Bragança Paulista: EDUSF, 2000, p. 244.

22 FRIEDRICH, Otto. A Cidade das Redes: Hollywood nos anos 40. Tradução: Ângela Melim. São Paulo: Companhia das Letras, 1988, p. 125.
}

${ }^{23}$ Cf. MENEguello, Cristina. Poeira de Estrelas: o cinema hollywoodiano na mídia brasileira das décadas de 40 e 50. Dissertação de mestrado. Campinas: Unicamp, 1992, p. 7.

${ }^{24}$ PINTO, Maria Inez Machado Borges. O Cinema, Tecnologias de Comunicação de Massa e Representações da São Paulo: Moderna. In: Anais do XIX Simpósio Nacional de História-ANPUH. História e Cidadania. São Paulo: Humanitas, 1998. Apud JUNQUEIRA, Mary Anne. Ao Sul do Rio Grande. Imaginando a América Latina em Seleções: oeste, wilderness e fronteira (1942-1970). Bragança Paulista: EDUSF, 2000, p. 41 
de autorização fornecido pelo mesmo para poder ser exibido, além de que o próprio órgão passou a produzir cinejornais favoráveis ao Estado Novo.

Durante os anos 1940, o Brasil era o terceiro país com maior número de espectadores de cinema do mundo ${ }^{25}$ e a exibição de filmes estadunidenses em cinemas nacionais cresceu rapidamente, até tornar-se mais comum, inclusive, do que a própria exibição de filmes brasileiros. Segundo Tota, no fim de 1940, todos os dezesseis cinemas de São Paulo exibiam filmes estadunidenses $^{26}$. Para Robert Sklar, o que levava as plateias estrangeiras a admirar os filmes de Hollywood eram as suas características de valores e estilos estadunidenses, como "sua velocidade, seu humor, sua petulância, seu fascínio, sua sátira e sua violência, seus espaços abertos e suas cidades cintilantes, seus cowboys e seus empresários"27.

Neste contexto, uma das funções de Hollywood para com o governo estadunidense estava em ser um instrumento de escape da situação da guerra, proporcionando entretenimento ao mesmo tempo em que introduzia o American way of life no imaginário latino-americano. Walt Disney e o seu cinema de animação mostraram se encaixar neste perfil e na qualidade de embaixador da Política de Boa Vizinhança, ele seria mais um dos pioneiros a trazer modernidade e civilização para a América Latina. Quando chegou ao Brasil, Disney se tornou sensação nas notícias nacionais, especialmente as cariocas. De acordo com o jornal A Manhã: "A ordem é Walt Disney. Não se fala em outra coisa na cidade. E está certo. O contrário seria um absurdo, seria a mesma coisa que se nós estivéssemos alheios ao que se passa na Europa"28. Assim, na medida em que a guerra ainda estava longe, a imprensa focava nos assuntos mais próximos ou, mais precisamente, interamericanos. Para citarmos um exemplo dos largos elogios de intelectuais brasileiros, em depoimento ao Correio Paulistano, Monteiro Lobato não poupou exageros:

Disney é a suprema compensação do nosso atual momento de horrores. Há a guerra, sim.

\footnotetext{
${ }^{25}$ Cf. MENEGUELLO, Cristina. Op. cit., p. 7.

${ }^{26}$ TOTA, Antonio Pedro. O Imperialismo Sedutor: a americanização do Brasil na época da Segunda Guerra. São Paulo: Companhia das Letras, 2000, p. 131.

${ }^{27}$ SKLAR, Robert. História Social do Cinema Americano. Tradução de Octavio Mendes Cajadó. São Paulo: Cultrix, 1975, p. 252.

28 "Walt Disney entrou na batucada - sugestões provocadas pela exibição da Escola de Samba de Portela". In: $A$ Manhã. Rio de Janeiro: Fundação Biblioteca Nacional, 26 ago. 1941, p. 5
} 
Há o bombardeio cego dos aviões. Há o infame estraçalhamento de crianças. Há o inferno: a Ciência a serviço do Mal. Mas a humanidade salva-se produzindo nesta hora trágica a altíssima compensação dum Disney, o Grande Criador ${ }^{29}$.

Dessa forma, em todos os periódicos existem muitos elogios ao sujeito Walt Disney, assim como aos estúdios Disney e ao lançamento de Fantasia no Brasil. Fantasia foi produzida por Disney em parceria com o famoso regente da Orquestra da Filadélfia, Leopold Stokowski (18821977). Em um estudo minucioso, Disney e Stokowski selecionaram composições que ganharam cores e movimentos. O resultado foi uma animação/musical colorida de 124 minutos, dividindo-se em sete excertos recortados pelas composições ${ }^{30}$. Assim, Fantasia é um longa-metragem composto por sete trechos de desenhos animados independentes entre si. Não é uma história de começo, meio e fim, mas sim vários excertos com histórias diferentes, cada uma delas comandadas por uma composição, em que todas juntas formam Fantasia. A animação quase não tem diálogos, pois a música está em destaque. Não são as músicas que acompanham as imagens, mas as imagens que acompanham as composições, estando estes dois elementos perfeitamente sincronizados. A música é o fator de produção de sentido em Fantasia ${ }^{31}$. O jornal Diário Carioca ressaltou o ineditismo da animação:

É um filme que o próprio pessoal de Disney não pode incluir em determinada categoria e isto porque se trata de uma espécie de filme para a qual não existem precedentes. Fantasia é, portanto, uma película, jamais realizada por quem quer que seja. Pelas informações que nos vêm de Hollywood, sabemos que nesse filme, Disney e seus artistas

\footnotetext{
${ }^{29}$ LOBATO, Monteiro. "Reação dum Troglodita". In: Correio Paulistano. São Paulo: Fundação Biblioteca Nacional, 16 set. 1941, p. 8.

${ }^{30}$ São as composições, respectivamente: Tocata em fuga em Ré menor, de Johann Sebastian Bach; Suíte de Quebra Nozes, de Pyotr Ilyich Tchaikovsky; Aprendiz de Feiticeiro, de Paul Dukas; Sagração da Primavera, de Igor Stravinsky; $A$ Pastoral, de Ludwig van Beethoven; Dança das Horas, de Amilcare Ponchielly; Noite do Monte Calvo, de Modeste Moussorgsky; e Ave Maria, de Franz Schubert.

${ }^{31}$ Há trabalhos que focam na produção de Fantasia, como: ALMEIDA, Melissa Ribeiro de. Quando a música fala: a produção de sentido em Fantasia. Monografia. Juiz de Fora: UFJF, 2002; PEGORARO, Celbi Vagner Melo. Fantasia e uma Nova Dimensão Sonora: Convergência de Linguagens Musical, Artística e Cinematográfica. Revista Anagrama: Revista Científica Interdisciplinar da Graduação. Edição 4. São Paulo: USP, 2012; SILVA, A. R.; CONTER, Marcelo Bergamin. Aprendizes do fantasia. Sessões do Imaginário, v. 16, p. 56-61, 2006.
} 
nos dão suas impressões de como um conjunto de composições famosas deve parecer. $\mathrm{E}$ também que, pela primeira vez uma música é filmada e não um filme é musicado ${ }^{32}$.

Justamente por ousar misturar animação e música clássica, quando estreou nos Estados Unidos, no dia 13 de novembro de 1940 no Teatro Broadway em Nova York, Fantasia recebeu muitas críticas negativas e causou grandes prejuízos para o estúdio, já que os baixos lucros não conseguiram suprir os altos custos de produção, calculados em mais de dois milhões de dólares ${ }^{33}$. Nas palavras do crítico Renato de Alencar, da revista A Scena Muda, Fantasia só podia ser uma obra feita por um poeta ou um louco. Poeta pelo lirismo que apresenta e louco justamente pela coragem do investimento ${ }^{34}$. A crítica estadunidense acusou Disney de arrogante e a animação de mau gosto com frases como "Uma chatice interminável" e "Um prejuízo para a boa música e para a arte da animação" 35 , entre outras.

Mas no Brasil não houve espaço para comentários negativos. Fantasia chegou como mais uma das ferramentas de propaganda do Office, e a partir do DIP, foi citada nos jornais e revistas sempre de maneira positiva. As primeiras notícias referentes a recepção de Fantasia começam em maio de 1941, quando funcionários técnicos de Disney estudaram casas de cinema do Rio de Janeiro e de São Paulo, um fato que de acordo com o Jornal do Brasil, foi inédito até então na cinematografia do país ${ }^{36}$. Os técnicos escolheram o Cinema Pathé Palace para a grande estreia no Rio de Janeiro, e o Cinema Rosário em São Paulo. Ambos os cinemas escolhidos eram localizados nos centros das cidades e destinados a um público elitizado, e a estreia de Fantasia aconteceu, portanto, como um evento de gala. O Cinema Rosário, por exemplo, era localizado no Edifício Martinelli, considerado o primeiro "arranha-céu" de São Paulo e assim como demais cinemas da

\footnotetext{
32 "O Gênio e mais uma de suas maravilhas: Disney 'desenha' a música clássica”. In: Diário Carioca. Rio de Janeiro: Fundação Biblioteca Nacional, 11 jul. 1941, p. 6.

${ }^{33}$ Cf. BRYMAN, Alan. Disney and his Worlds. London: Routledge, 1995, p. 8. ${ }^{34}$ ALENCAR, Renato de. "Fantasia - Walt Disney". In: A Scena Muda. Rio de Janeiro: Fundação Biblioteca Nacional. 02
set. 1941, p. 30.
}

${ }^{35}$ Frases citadas no documentário "Walt Disney - o sonho de um homem", 1982. Apud PEGORARO, Celbi Vagner Melo. Fantasia e uma Nova Dimensão Sonora: Convergência de Linguagens Musical, Artística e Cinematográfica .Revista Anagrama: Revista Científica Interdisciplinar da Graduação. Edição 4. São Paulo: USP, 2012, p. 7.

36 “Os próprios técnicos do Studio de Walt Disney escolheram as casas, no Rio e em São Paulo onde 'Fantasia' deverá ser exibida”. In: Jornal do Brasil. Rio de Janeiro: Fundação Biblioteca Nacional, 20 jul. 1941, p. 7. 
extinta Cinelândia da cidade, nessa época exigia que os espectadores masculinos vestissem terno e gravata, e as mulheres colares de pérolas ${ }^{37}$.

No Pathé Palace, o lançamento de Fantasia contou a presença do presidente da República, assim como da primeira-dama, Darcy Vargas, e demais autoridades do Estado.

Imagem 1: Getúlio Vargas, Darcy Vargas, Walt Disney, e a esposa Lillian Disney na estreia de Fantasia no Cinema Pathé Palace.

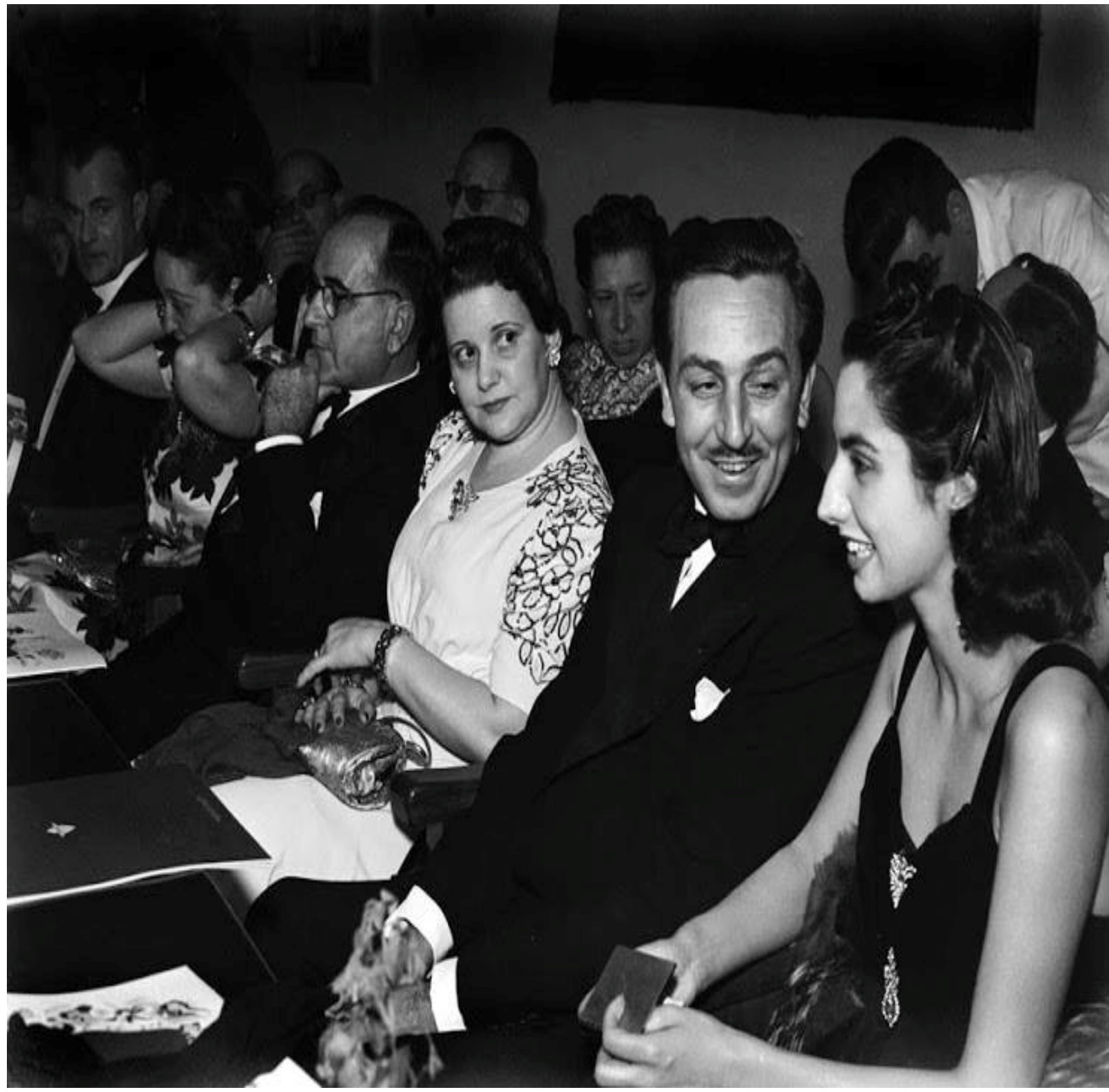

Fonte: História em Fotos ${ }^{38}$.

${ }^{37}$ Cf. MENEGUELLO, Cristina. Poeira de Estrelas: o cinema hollywoodiano na mídia brasileira das décadas de 40 e 50. Dissertação de mestrado. Campinas: Unicamp, 1992, p. 53. 
Assim, podemos afirmar que neste primeiro momento apenas as classes altas cariocas e paulistanas tiveram a oportunidade de assistir à Fantasia. Segundo o Diário Carioca, no começo os ingressos do Cinema Pathé custaram 100 mil réis $^{39}$. De acordo com o Correio Paulistano, os primeiros preços da entrada no Cinema Rosário foram de 10 mil réis para as poltronas, e a 06 mil réis para crianças, estudantes e outras meias entradas ${ }^{40}$. Segundo o historiador Benedito Barbosa Pupo, com mil réis era possível adquirir muitos bens materiais durante o Estado Novo, e com 100 mil réis, para fazermos uma comparação, era possível alugar uma boa casa em área nobre de Campinas $(\mathrm{SP})^{41}$.

Entretanto, era interesse do governo que muitos tivessem acesso ao que os bons vizinhos tinham a nos oferecer, por isso, o DIP veiculava a propaganda não apenas por meio dos jornais e revistas, mas também do rádio ${ }^{42}$ e de todos os demais meios de comunicação possíveis. Para obter mais êxito, a mídia também defendia que a música clássica presente na animação não seria uma limitação de público, e sim um convite para esta ser vista por todas as classes, sem exceção:

É um erro pensar que Fantasia é um espetáculo para elites apenas, porque, se bem que se trate de música clássica, executada por uma Orquestra Sinfônica, o filme de Disney tem todas as características para agradar mesmo aqueles que não apreciam ou não entendem essa espécie de música. Aliás, foi intenção de Disney e de Stokowski, ao fazerem Fantasia,

38 Disponível em: < http://historiaemfotos.tumblr.com/post/37666064338/walt-disney-com-sua-esposa-lillian-e-opresidente> Acesso em 06 de junho de 2015.

39 "Uma noite de esplendor, a primeira exibição de 'Fantasia' - Quase esgotada a lotação do Pathé Palace". In: Diário Carioca. Rio de Janeiro: Fundação Biblioteca Nacional, 20 ago. 1941, p. 6.

40 "Tomem nota dos preços para 'Fantasia'". In: Correio Paulistano. Rio de Janeiro: Fundação Biblioteca Nacional, 26 ago. 1941 , p. 8.

${ }^{41}$ Esse dado refere-se a década de 1920. Na ausência de comparação mais adequada, utilizamos esta como parâmetro para constatar o alto valor de 100 mil réis para o ingresso da estreia de Fantasia. Cf. PUPO, Benedito Barbosa. Os serviços e o comércio no tempo de mil réis. In: 8 bananas por um tostão. Campinas: Prefeitura Municipal, 1976. pp. 45-8.

42 Um exemplo de programa de rádio era o Repórter Esso, um radiojornal que estreou em 28 de agosto de 1941, ainda durante a estadia de Disney no Brasil, e durou até 1968, que era patrocinado pela Standard Oil New Jersey (Esso) e noticiava os principais fatos sociais, políticos e econômicos de interesse não só do país, como do mundo. Conhecido por ser a primeira síntese noticiosa globalizante, o programa já existia nos Estados Unidos desde 1935 e foi veiculado posteriormente na Argentina, no Uruguai e no Chile, além do Brasil. Repórter Esso estava subordinado a Agência Nacional de Informações, fazia chamadas de hora em hora e transmitia os interesses da política da Boa Vizinhançana programação radiofônica desses países. 
tornar a música clássica mais acessível ás camadas menos cultas (sob o ponto de vista musical), tornando-a ainda aptas a melhor entenderem, para o futuro, esse gênero de música ${ }^{43}$.

Apesar de ser um exagero dizer que todos assistiram à Fantasia, após as elegantes estréias a animação realmente passou a ser exibida em outras salas de cinema mais simples e baratas e, assim, partes dos demais segmentos da população puderam assistir à animação algumas semanas depois. Esse tempo varia de acordo com a região do país, sendo mais demorado para os locais mais interioranos. Segundo a mídia, em algumas semanas Fantasia tornou-se, então, um sucesso de recepção no Brasil.

Nos periódicos são ausentes quaisquer reclamações da população sobre as exibições; elogios, ao contrário, mesmo de quem conseguiu assistir à animação apenas meses depois da estreia, são numerosos. Para citar um exemplo, na revista $A$ Scena Muda, em uma página reservada para os leitores escreverem as suas próprias críticas, o baiano que assina Zoroastro G. Figueredo lamentou que Fantasia só chegou a Salvador no ano seguinte, em 1942. E o pior, que o cinema utilizado não tinha os recursos necessários para a exibição, o que acarretou em um declínio da qualidade do filme. Mesmo assim, ele adorou Fantasia:

[...] infelizmente, vi "Fantasia" num dos nossos piores aparelhos cinematográficos, mas felizmente, vi "Fantasia". [...] Ansioso que estava por conhecer essa esplendida fita, sirvome agora da presente para dizer que é tão bela que um sentimento de piedade e tristeza se me envolve, ao pensar que existem pelo mundo inteiro milhares de ceguinhos, privados de verem uma verdadeira beleza, tão linda quanto indescritível, porque não há imaginação que possa concebê-la, tamanha é a sua magnificente espetaculação! [sic] ${ }^{44}$

A intensa propaganda sobre Fantasia aliada aos vastos elogios do seu criador, Walt Disney, por parte dos meios de comunicação brasileiros são boas razões para explicarmos o sucesso de recepção desta animação no Brasil, contrariando e omitindo o escasso público que a mesma obteve em seu próprio país. Enquanto Fantasia encontrava-se nos cinemas, Walt Disney estava

\footnotetext{
43 “'Fantasia', um espetáculo para todas as classes". In: Jornal do Brasil. Rio de Janeiro: Fundação Biblioteca Nacional, 29 jul. 1941, p. 11.

${ }^{44}$ FIGUEREDO, Zoroastro G. "Fantasia". In: A Scena Muda. Rio de Janeiro: Fundação Biblioteca Nacional, 09 jun. 1942, p. 10.
} 
ocupado cumprindo os projetos do governo estadunidense. Em primeiro lugar, Disney estava procurando um animal que pudesse representar os brasileiros na forma de personagem para as suas futuras animações que naquele momento já estavam encomendadas pelo governo estadunidense - Alô, Amigos (1942) ${ }^{45}$ e Você já foi à Bahia? (1944) ${ }^{46}$. Durante a sua estadia ao Brasil, portanto, o personagem escolhido por Disney foi o papagaio Zé Carioca.

Disney também participou de conferências na ABI - a Associação Brasileira de Imprensa; no DIP; no Itamarati; no Ministério da Educação; conheceu Ary Barroso e Grande Otelo; visitou a Escola de Samba da Portela; prestigiou corridas de cavalo no Jockey Club; e foi condecorado pelo próprio Getúlio Vargas ao receber a Ordem Nacional do Cruzeiro do Sul47. Disney ainda reservou tempo para se misturar a população e, é claro, ser fotografado nesta situação, contribuindo para reforçar as afirmações dos periódicos em relação à sua simpatia com os latino-americanos, como um verdadeiro bom vizinho. Na seguinte fotografia, o desenhista estava deitado na areia da praia de Copacabana, no Rio de Janeiro, com uma câmera na mão que usava para interagir com os guarda-vidas da praia (ao fundo):

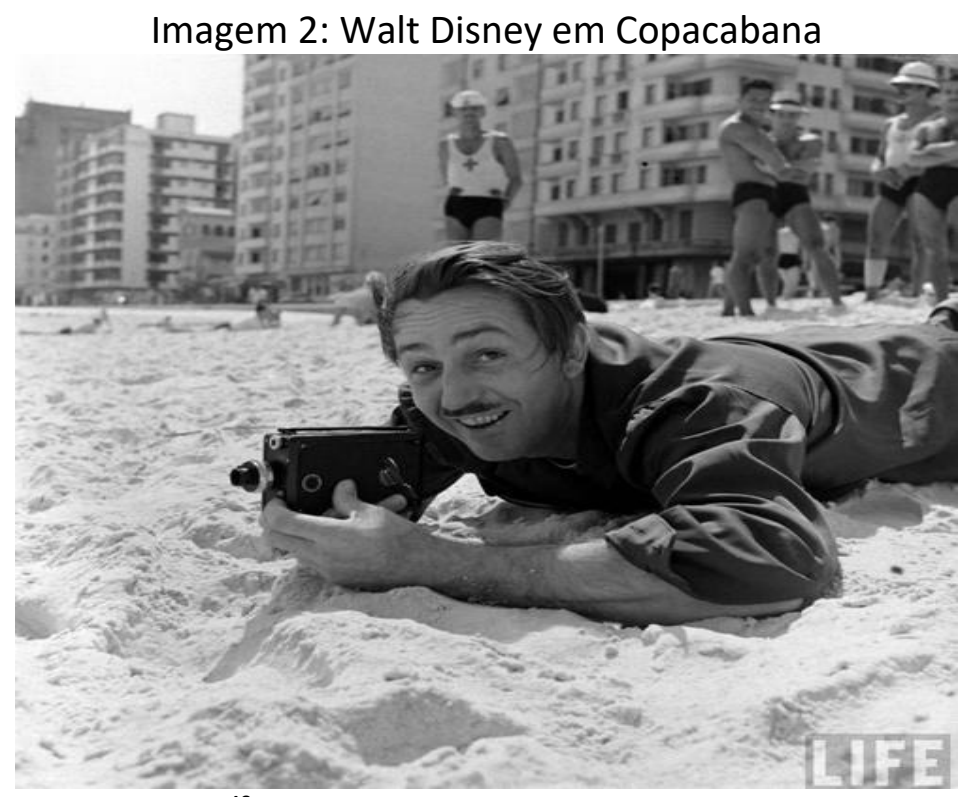

Fonte: Sobrasa ${ }^{48}$

\footnotetext{
${ }^{45}$ Disponível em < https://www.youtube.com/watch?v=CODjUuOY6vs $>$ Acesso em 12/05/2017.

${ }^{46}$ Disponível em < https://www.youtube.com/watch?v=BeK_1cUX8mY> Acesso em 12/05/2017.

${ }^{47} \mathrm{O}$ mais alto título brasileiro que homenageia personalidades estrangeiras.

48 SZPILMAN, David. Disney e os guarda-vidas da praia-Rio 1941. Sobrasa. 07 de dezembro de 2012. Disponível em: <http://www.sobrasa.org/portfolio/disney-e-os-guarda-vidas-da-praia-rio-1941/> Acesso em 12 de junho de 2015.
} 
Esta e demais fotos da estadia de Walt Disney ao Brasil são de autoria do fotógrafo Hart Preston, da revista Life, que acompanhou a equipe do desenhista na viagem. Essas imagens eram também encomendadas pelo Office para exaltar as belezas naturais do Rio de Janeiro em uma importante revista para o público estadunidense. Nota-se, aliás, que todos os fotografados possuem pele branca, ou, no máximo, bronzeadas pelo sol de Copacabana, sendo um convite para o turismo ao Rio de Janeiro.

Além destas, havia ainda mais uma razão que nos ajuda a entender o sucesso de Fantasia no Brasil. Fantasia foi criada para ser o primeiro longa-metragem com a participação de Mickey, personagem que já vinha se estabilizando como o chefe da hierarquia do mundo de Disney. No papel de Aprendiz de Feiticeiro, composição de Paul Dukas, Mickey é um aprendiz que, sobrecarregado de tarefas, apropria-se dos poderes mágicos do seu mestre, sem o consentimento deste, concedendo vida a alguns utensílios domésticos para que esses fizessem o seu trabalho. Ao observarmos o pôster oficial de Fantasia lançado em 1940 nos Estados Unidos, percebemos que Mickey é a figura de destaque, logo abaixo dos nomes "Walt Disney" e "Fantasia", ao lado do nome de "Stokowski", e acima e com dimensões maiores dos demais personagens: 
Imagem 3 - Pôster oficial de Fantasia.

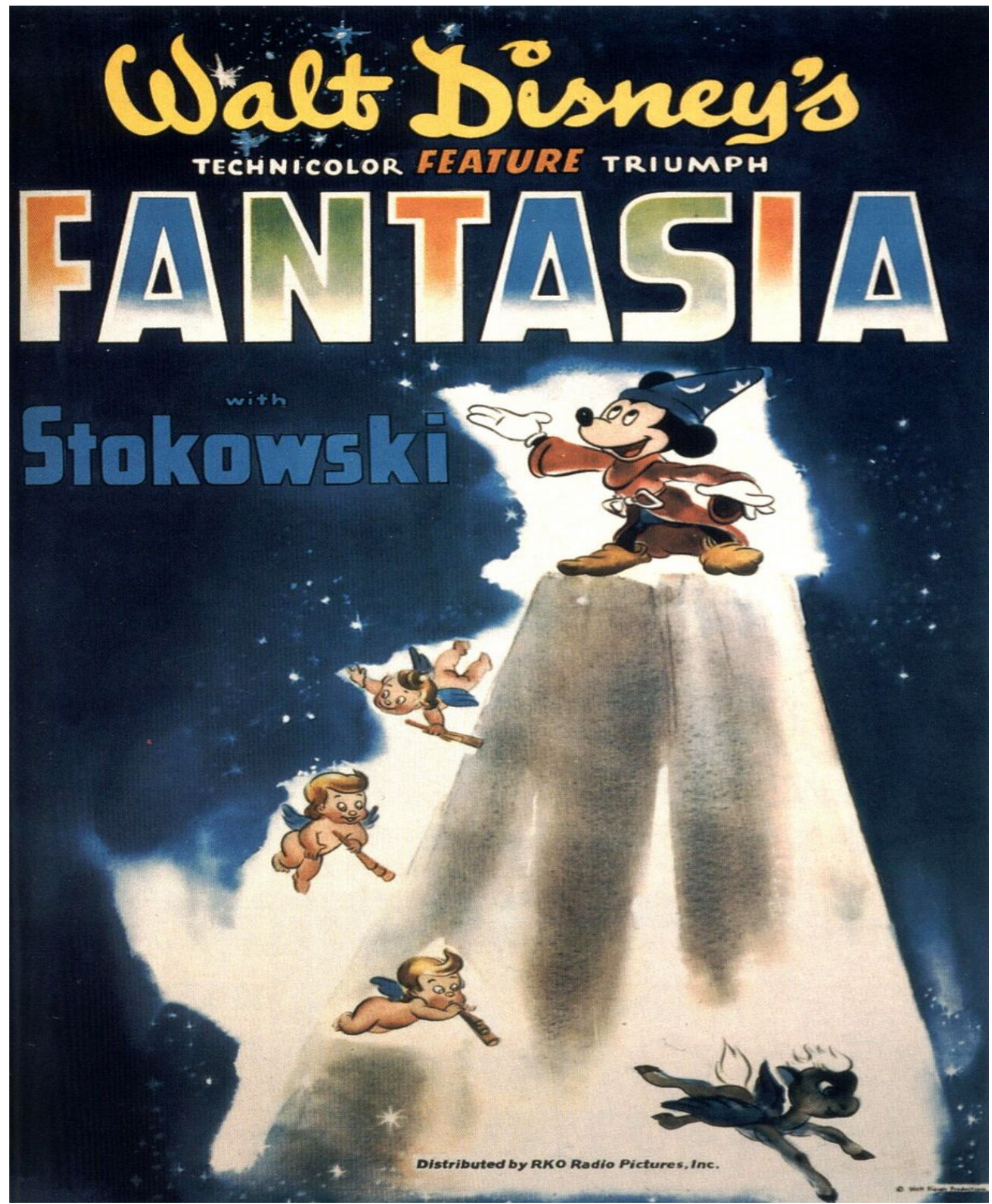

Fonte: IMDB ${ }^{49}$

${ }^{49}$ Disponível em: < http://www.imdb.com/title/tt0032455/mediaviewer/rm1186985216> Acesso em 31 de julho de 2016. 
A grande estrela do pôster e da animação é Mickey Mouse. O chapéu do camundongo, que contém desenhos da lua e estrelas, representa o mundo de sonhos que transporta o público para as "fantasias" da animação ${ }^{50}$. Segundo Ariel Dorfman e Armand Matterlart, no mundo de Disney, Mickey é a "imagem de permanência, é a lei particularista que invade e recobre tudo"51. Esta permanência está presente no cotidiano do seu país natal, o hegemônico, e nos países subordinados a partir de diversos meios. No Brasil, Mickey começou a marcar presença em tirinhas nos rodapés de jornais, em bonecos e brinquedos diversos e em propagandas de produtos de todos os tipos.

Apesar de Fantasia não ser um conto de fadas clássico, como a maioria dos filmes de Disney, no segmento $O$ Aprendiz de Feiticeiro, Mickey termina a sua cena com uma lição de moral ao espectador. Hollywood trabalhou e trabalha na construção de uma identidade nacional estadunidense e, nesse caso, Mickey é o mocinho e o exemplo a ser seguido. Desde o lançamento de Fantasia, a moral de Disney representada por Mickey já era percebida, ao menos, pela mídia especializada. A Scena Muda era uma importante revista brasileira sobre cinema, que divulgou essa característica das animações de Disney de maneira não apenas positiva, mas superior:

De todos os fabricantes de desenhos animados, Walt Disney é o mais aplaudido. Suas comédias, seus dramas, suas fantasias não se confundem com o restante dos fazedores de cartoons, quase sempre de uma insipidez e imbecilidade insuportáveis. Os de Disney, ao contrário, se caracterizam pelo sentido humano, pela graça do tema, pela grande beleza moral do argumento ${ }^{52}$.

Dessa maneira, Disney colaborou para reforçar o imaginário social estadunidense no Brasil. Concluímos que Fantasia foi um sucesso de recepção que abriu portas para as futuras animações da Walt Disney Productions no país em razão da grande positividade da mídia em relação à obra. $\mathrm{A}$

\footnotetext{
${ }^{50}$ Cf. PEGORARO, Celbi Vagner Melo. Fantasia e uma Nova Dimensão Sonora: Convergência de Linguagens Musical, Artística e Cinematográfica. Revista Anagrama: Revista Científica Interdisciplinar da Graduação. Edição 4. São Paulo: USP, 2012, p. 89.
}

51 DORFMAN, Ariel; MATTELART, Armand. Para Ler o Pato Donald: Comunicação de massa e colonialismo. Tradução de Álvaro de Moyá. 2ª ed. Rio de Janeiro: Paz e Terra, 1980, p. 133.

52 “Desenhos animados para o Brasil”. In: A Scena Muda, 17 de março de 1942, p. 3. 
partir de então, a imagem de Mickey Mouse ficaria marcada como um dos principais símbolos do imaginário estadunidense e se consolidaria como o principal personagem da história do cinema de animação de todos os tempos, podendo ser reconhecido, desde a Segunda Guerra Mundial, em todas as partes do mundo.

\section{Referências:}

CAPELATO, Maria Helena. A imprensa na história do Brasil. São Paulo: Contexto/EDUSP, 2 edição: 1994.

Propaganda Política e Controle dos Meios de Comunicação. In: PANDOLFI, Dulce (Org.). Repensando o Estado Novo. Rio de Janeiro: Fundação Getúlio Vargas, 1999, pp. 167-178.

CHAMBÔ, Pedro Luis. O Estado de Exceção como Regra - um estudo histórico-constitucional do Estado Novo (1937-1945). R. Fac. Dir. Univ. São Paulo, v. 108, pp. 117-128, 2013.

DORFMAN, Ariel; MATTELART, Armand. Para Ler o Pato Donald: Comunicação de massa e colonialismo. Tradução de Álvaro de Moyá. 2a ed. Rio de Janeiro: Paz e Terra, 1980.

FRIEDRICH, Otto. A Cidade das Redes: Hollywood nos anos 40. Tradução: Ângela Melim. São Paulo: Companhia das Letras, 1988.

GABLER, Neal. Walt Disney: O triunfo da imaginação americana. Tradução: Ana Maria Mandim. Osasco, SP: Novo Século, 2013.

JUNQUEIRA, Mary Anne. Ao Sul do Rio Grande. Imaginando a América Latina em Seleções: oeste, wilderness e fronteira (1942-1970). Bragança Paulista: EDUSF, 2000.

MARTíN-BARBERO, Jesús. Dos meios às mediações: comunicação, cultura e hegemonia. Tradução de Ronald Polito e Sérgio Alcides. Rio de Janeiro: Editora UFRJ, 2009. 
MENEGUELLO, Cristina. Poeira de Estrelas: o cinema hollywoodiano na mídia brasileira das décadas de 40 e 50. Dissertação de mestrado. Campinas: Unicamp, 1992.

MOURA, Gerson. Relações Exteriores do Brasil - 1939-1950: Mudanças na natureza das relações Brasil Estados Unidos durante e após a Segunda Guerra Mundial. Brasília: FUNAG, 2012.

- Tio Sam Chega ao Brasil: A penetração cultural americana. São Paulo: Brasiliense, 2a edição, 1985.

PEGORARO, Celbi Vagner Melo. Fantasia e uma Nova Dimensão Sonora: Convergência de Linguagens Musical, Artística e Cinematográfica. Revista Anagrama: Revista Científica Interdisciplinar da Graduação. Edição 4. São Paulo: USP, 2012.

TOTA, Antonio Pedro. O Imperialismo Sedutor: a americanização do Brasil na época da Segunda Guerra. São Paulo: Companhia das Letras, 2000.

SKLAR, Robert. História Social do Cinema Americano. Tradução de Octavio Mendes Cajadó. São Paulo: Cultrix, 1975.

\subsection{Animação}

FANTASIA (Fantasia). Burbank: Walt Disney Productions, 1940. Direção: Samuel Armstrong, James Algar, Bill Roberts, Ben Sharpsteen, David Hand, Hamilton Luske, Jim Handley, Ford Beebe, T. Hee, Norman Ferguson, Paul Satterfield e Wilfred Jackson. Roteiro: Joe Grant, Dick Huemer. Elenco e Trilha Sonora: The Philadelphia Orchestra, dirigida por Leopold Stokowski. Distribuição: RKO Radio Pictures. Animação/Musical. Cor. 124 min.

\subsection{Periódicos}

A MANHÃ. Rio de Janeiro: Fundação Biblioteca Nacional, 1941-1945. PR_SPR_00007_116408. Disponível em: 
<http://memoria.bn.br/DocReader/docreader.aspx?bib=116408\&pasta=ano\%20194>

Acesso entre julho de 2013 e abril de 2014.

A SCENA MUDA. Rio de Janeiro: Fundação Biblioteca Nacional, 1941-1945. PR_SPR_02338_084859. Disponível em: <http://memoria.bn.br/DocReader/docreader.aspx?bib=084859\&pasta=ano\%20194> Acesso em agosto de 2016.

CORREIO PAULISTANO. São Paulo: Fundação Biblioteca Nacional, 1941-1942. PR_SPR_00140_090972. Disponível em: 58<http://memoria.bn.br/DocReader/docreader.aspx?bib=090972_09\&pasta=ano\%2019>Acesso em agosto de 2016.

DIÁRIO CARIOCA. Rio de Janeiro: Fundação Biblioteca Nacional, 1941-1945. PR_SPR_00009_093092. Disponível em: <http://memoria.bn.br/DocReader/docreader.aspx?bib=093092_03\&pasta=ano\%20194> Acesso entre julho de 2013 e abril de 2014.

JORNAL DO BRASIL. Rio de Janeiro: Fundação Biblioteca Nacional, 1941-1945. PRC_SPR_00009_030015. Disponível em: <http://memoria.bn.br/DocReader/docreader.aspx?bib=030015_06\&pasta=ano\%20194> Acesso entre julho de 2013 e abril de 2014.

\subsection{Sites (fontes de imagens)}

História em Fotos - Disponível em: < http://historiaemfotos.tumblr.com/post/37666064338/waltdisney-com-sua-esposa-lillian-e-o-presidente> Acesso em 06 de junho de 2015.

IMDB - Disponível em: <http://www.imdb.com/title/tt0032455/mediaviewer/rm1186985216> Acesso em 31 de julho de 2016.

Sobrasa - Disponível em: <http://www.sobrasa.org/portfolio/disney-e-os-guarda-vidas-da-praiario-1941/> Acesso em 12 de junho de 2015. 